\title{
Pregnancy Outcomes Among The Ibani Of Rivers State, Nigeria: Findings From Case-Studies
}

\author{
Ezebunwa E. Nwokocha, Ph.D \\ Department of Sociology, \\ University of Ibadan \\ Nigeria.
}

\begin{abstract}
The prevalence of high maternal and infant morbidity/mortality among the Ibani of Rivers State, Nigeria, is linked to socio-cultural factors that influence perceptions, attitudes and practices of the people with regard to pregnancy. This study investigates the factors affecting pregnancy outcomes among the Ibani by examining 19 cases identified through Exit-interviews (EIs). Findings indicate that pregnancy outcomes depend on the interaction of complex variables such as male role, socioeconomic status of women, child spacing, access and use of maternal health facilities, among others. The results show that there are 4 principal types of pregnancy outcomes among the Ibani, which include: Type-1 representing maternal and infant survival; Type- 2 which is synonymous with maternal survival but infant mortality; Type-3 or spontaneous abortion; and Type- 4 which represents maternal mortality but infant survival. The findings suggest that multiple social, cultural and ideological factors condition behaviours among the Ibani and that pregnancy outcomes are only comprehensively understood in the context they occur.
\end{abstract}

\section{Background}

Pregnancy outcomes rank among the most pressing reproductive health problems in the world. Globally, an annual estimate of 600,000 women aged 15 - 49 die of pregnancy-related causes, with 99 percent coming from the developing world (Population Reference Bureau, 2002; WHO, 2000; Addai, 1998; Wall 1998; Salter et al., 1997) and Nigeria alone accounting for 10 percent of this total (Okolocha et al., 1998).

Pregnancy outcomes may undermine family stability at the institutional level, and health and manpower needs of societies at the structural. Both impacts have implications for individuals living in relevant communities. The World Bank (1998) had observed that maternal and infant mortality depend to a large extent on whether women have access to information, education and communication resources they need to provide themselves and their infants with adequate care. This shows that the achievement of safe motherhood among women results from the interaction of several factors in the relevant societies. Apart from the conditions of health centres and the factors that affect their use or non-use, socioeconomic status of women is also strongly associated with pregnancy outcomes 
Maternal situation in Ibani society is exacerbated by patriarchy which gives men power over women in virtually all spheres of family life. The exclusion of women from some sensitive family discourse, such as family planning, family size and access and use of maternal health facilities, is usually hinged on cultural beliefs and values designed and sustained by men in order to maintain their domination and subjugation of women (IsiugoAbanihe, 2003; Moore and Helzner, 1996; Sen et al., 1994). This study highlights communal and personal values, perceptions, beliefs and practices related to pregnancy among the Ibani of Rivers State through the convergence of Demography, Medical Sociology and Ethnography.

\section{Materials and Method}

\section{Ethnographic profile}

The study was conducted in Rivers State of Nigeria which has 23 local government areas (LGAs) with a population of 3,187,864, according to the 1991 census. This research was, specifically, undertaken among the Ibani, who constitute an ethnic group (Otite, 2000) and inhabit the Bonny Island, which consists of 14 Kingdoms (Alagoa and Fombo, 2001; Adeyemo, 2000). The Ibani are predominantly subsistent farmers and fisher men and women. Ibani men and women are engaged in these activities, as clear-cut division of labour along sex lines is not very evident. An average Ibani woman in the village community is illiterate and hardly takes active part in family and reproductive health decisions. Although the Ibani are patriarchal, men still value their daughters highly. This explains the basis of a local aphorism ereibim, meaning literarily "woman is good" (Banigo, 1996:54); male child preference is not explicitly emphasized among the people. However, Ibani women, given the premium placed on children, generally prefer a large family size.

Ibani people are rich in culture. The most celebrated festival among this people is Nwaotam in which bona-fide Ibani sons and daughters, in a colourful display of culture, accompany their masquerade into the river as directed by the god of their land. Pregnant women are prohibited from both seeing the masquerade and taking part in the festivity or face the wrath of Ikuba god whose shrine is located at the Ikuba square. This prohibition has implications for access and use of maternal health facilities especially during emergencies. The cosmology of Ibani people is better understood by examining their religious practice. At the apex of religious worship is the supreme God (Tamuno) believed to transcendentally relate with the Ikuba god - symbolically represented by the Iguana. The Ikuba priest has the exclusive permission of attending to and communing with the god on unlimited areas of human activities. The people hold this exclusive right sacrosanct. According to the Ikuba priest, attitudes and behaviour follow the 
State, Nigeria: Findings from Case-Studies

god's injunctions, while anti-normative activities which constitute cultural taboos are punished as directed by the god.

There is a belief among the Ibani that the placenta that follows childbirth should of necessity be buried beside an economic tree. For the people, this serves two purposes: it is believed that like the tree, the child would be fruitful and also live long. People whose placentas cannot be accounted for are said to be threatened with barrenness and untimely death. The perception among a large majority of Ibani people is that TBAs give placentas (after birth) more readily to parents of babies for proper traditional disposal than other birth attendants, as a result of which they are preferred for child delivery.

Ibani women were chosen as the central focus of the study because, leaving in an environment that lacks modern maternal health facilities, they are in many circumstances exposed to life threatening conditions. In addition, transportation from Ibani villages to Bonny Headquarters, where the available hospitals are located, is usually by canoe since no motor roads link these locations. The reality is that, even in emergencies, the only available means of transport is the canoe, which takes about two and half hours to move a patient to the nearest hospital. Certainly, this could worsen an already bad situation. The situation is exacerbated by some cultural beliefs and practices - related to placenta, Nwaotam festival, food and nutrition, among others - that affect activities of women in the society. The research examined 19 pregnant women at different trimesters through the case-study method as a way to understanding pregnancy related issues among the people.

\section{$\underline{\text { Data collection method }}$}

Cases examined for the study were selected after engaging them in Exitinterviews (EIs). An Exit-interview is a method in which persons who fall within the target of a study (usually related to health) are interviewed at the point they leave a health facility after examination and/or treatment, in order for the researcher to establish their health status or knowledge (Nwokocha, 2004). The purpose of such investigation is to identify relevant cases to be followed-up over time with regard to a particular health condition. Demographers and Medical Sociologists employ this technique of data collection in situations requiring establishment of concrete cases for further examination. This technique facilitated comparison of the health status of identified cases over the period of study and helped relate key factors to changes in pregnancy status. 
Interviews were conducted in fifteen Traditional Birth Clinics (TBCs) with at least one of such clinics in each of the 14 villages selected. Although health centres exist in the study area, interviews could not take place in such facilities as a result of very low (and most times none) patronage. The interviews, which emphasized anonymity of respondents, lasted about one hour with interviewees discussing issues related to male role, socioeconomic status, child spacing, prenatal activities and access and use of facilities, among others. In all the facilities, attempts were made to engage TBAs in discussions in order to ascertain their level of perception and involvement in maternal care.

Through this method, two categories of women in their various trimesters were identified. One category comprised 7 cases with records of pregnancy-related complications. The remaining 12 -second category- at the time of their identification had normal pregnancy-record. Fieldwork/data collection for the study lasted about ten months. The reason is that although it takes nine months to carry pregnancy to term, pregnancy outcomes are assessed at the end of the postpartum period (six weeks after delivery).

\section{Clarifying the concept of pregnancy outcomes}

In this study, pregnancy outcomes refer to the results of conceptions. What becomes of a pregnancy from conception through delivery to the end of the postpartum period is regarded as its outcomes. Such outcomes are classified into types 1, 2, 3 and 4 in the present analysis. Type- 1 outcome occurs when both the mother and her baby survive the risks associated with pregnancy and live for up to six weeks following delivery. Deaths of either women or children or both after 42 days of delivery are usually not classified as pregnancy related. The reason is that after this period, mothers and their babies would have adjusted to normal body conditions. Types 2, 3 and 4 pregnancy outcomes, on the other hand, are associated with maternal and or infant mortality (including fetal mortality, miscarriage, stillbirth etc). Specifically, Type-2 signifies mother's survival but infant mortality; Type-3 outcome is synonymous with spontaneous abortion; and Type- 4 outcome represents maternal mortality but infant survival. These outcomes are presented in Table 1 for clarity. 
State, Nigeria: Findings from Case-Studies

Table 1: Pregnancy Outcomes by Types and Descriptions

\begin{tabular}{|l|l|}
\hline Pregnancy Outcomes & Descriptions \\
\hline Type-1 & Synonymous with maternal and infant survival. \\
\hline Type-2 & Represents maternal survival but infant mortality. \\
\hline Type-3 & Signifies spontaneous abortion. \\
\hline Type-4 & Represented by maternal mortality but infant survival. \\
\hline
\end{tabular}

The main reason for describing pregnancy outcomes rather than categorizing them into desired and undesired and/or successful and unsuccessful, is that the interpretation given to these events varies along the expectations of individual(s) who have stake in such outcomes. For instance, a couple, who for some reason, does not desire a particular pregnancy, might interpret spontaneous abortion as a desired outcome. For such a couple, a live-birth would invariably mean undesired outcome. A different interpretation may, however, be given to the same outcome by another couple who have entirely different desires. Circumventing this ambiguity requires that the type of pregnancy outcome(s) experienced by each woman be described rather than categorized, adapting ethnographic conventions governing genealogies.

Analysis of case-studies involved detailed examination of some variables that highlight the relationship between a range of socio-cultural factors and pregnancy outcomes. An attempt was made to investigate some background information about identified cases in order to identify their associations with pregnancy outcomes. Preliminary data covered variables such as age, educational qualification, occupation and income, age at marriage, values, religion and beliefs and practices.

\section{Results and Discussions}

To ensure some level of representativeness, at least one case was identified from each of the 14 villages that make up Ibani society. Table 2 reveals various characteristics among selected cases and pregnancy outcomes. Pseudonyms have been used to identify individual cases in line with ethical ethnographic requirements. The variables examined among the 19 identified cases include: names of villages of origin, educational qualifications, trimester on identification for the study, sources of prenatal care, pregnancy statuses and pregnancy outcomes. Of this total, 12 had normal pregnancy (NP) status at the time of identification, while the other 7 cases were identified as having complications at the period. 
Table 2 indicates that the study cuts across the 14 kingdoms of Bonny (Ibani society), with at least one woman from each of the villages included in the study. However, in Ibanigo, LongJohn, Wilcox, Dublin Green and Allison villages, two cases were examined due to availability and willingness of these additional participants to be involved in the study.

Among the five cases identified during their first trimester, four had primary school education while one had incomplete secondary school education. All respondents in the first trimester group were attended to by traditional birth attendants (TBAs) for prenatal care. In addition, three had normal pregnancy records at the time of identification while two had complications. Except for Gberebima, whose pregnancy status changed from identified complication (IC) to normal pregnancy (NP), others maintained their identified status till delivery. Among the cases in this category, only Ibifa had spontaneous abortion, others experienced Type-1 pregnancy outcome. 
Table 2: Distribution of Cases by Selected Characteristics and Pregnancy-Outcomes

\begin{tabular}{|c|c|c|c|c|c|c|c|c|}
\hline \multirow{2}{*}{$\begin{array}{l}\text { Names Of } \\
\text { Women }\end{array}$} & \multirow{2}{*}{$\begin{array}{l}\text { Village Of } \\
\text { Origin }\end{array}$} & \multirow{2}{*}{$\begin{array}{l}\text { Educational } \\
\text { qualification }\end{array}$} & \multirow{2}{*}{$\begin{array}{l}\text { Trimest } \\
\text { er }\end{array}$} & \multirow{2}{*}{$\begin{array}{c}\text { Sources of } \\
\text { prenatal care }\end{array}$} & \multicolumn{3}{|c|}{ Pregnancy status } & \multirow{2}{*}{$\begin{array}{l}\text { Pregnancy } \\
\text { Outcomes }\end{array}$} \\
\hline & & & & & Normal & $\begin{array}{c}\text { Cases Of } \\
\text { Complications }\end{array}$ & $\begin{array}{l}\text { Changes in } \\
\text { pregnancy } \\
\text { status }\end{array}$ & \\
\hline Ibifa & Ibanigo & Pri Complete & First & TBA & - & IC & NIL & $\begin{array}{l}\text { Spontaneous } \\
\text { Abortion }\end{array}$ \\
\hline Ikpo & Bristol & Pri. Incomplete & , & " & NP & - & NIL & $\begin{array}{l}\text { Mother and baby } \\
\text { survived after } 6 \\
\text { weeks of birth }\end{array}$ \\
\hline Dimanye & LongJohn & " & $\prime \prime$ & $\prime \prime$ & NP & - & NIL & " \\
\hline $\begin{array}{l}\text { Gberebim } \\
\text { a }\end{array}$ & $\begin{array}{l}\text { Dick } \\
\text { Tolofari }\end{array}$ & Pri. Complete & " & " & - & IC & $\mathrm{NP}$ & " \\
\hline Edith & Brown & $\begin{array}{c}\text { Sec. } \\
\text { Incomplete } \\
\end{array}$ & " & , & $\mathrm{NP}$ & - & NIL & ", \\
\hline Alale & Wilcox & No Education & Second & 1 & $\mathrm{NP}$ & - & NIL & , \\
\hline Nengi & $\begin{array}{l}\text { Finecount } \\
\text { ry }\end{array}$ & Pri. Incomplete & " & " & NP & - & NIL & $"$ \\
\hline Nwaeresi & $\begin{array}{l}\text { Adongo } \\
\text { Hart }\end{array}$ & , & " & TBA/HC & NP & - & IC & Still Birth \\
\hline Erengesi & $\begin{array}{l}\text { Sincimina } \\
\text { bo-Ofori }\end{array}$ & $\begin{array}{c}\text { Sec. } \\
\text { Incomplete }\end{array}$ & , & TBA & - & IC & $\mathrm{NP}$ & $\begin{array}{l}\text { Mother and baby } \\
\text { survived after } 6 \\
\text { weeks of birth }\end{array}$ \\
\hline
\end{tabular}




\begin{tabular}{|c|c|c|c|c|c|c|c|c|}
\hline Nwayinna & $\begin{array}{l}\text { Dublin } \\
\text { Green }\end{array}$ & Pri. Complete & " & " & - & IC & NIL & Perinatal Death \\
\hline Ekeremo & Allison & Pri. Incomplete & " & $\prime \prime$ & $\mathrm{NP}$ & - & NIL & $\begin{array}{l}\text { Mother and baby } \\
\text { survived after } 6 \\
\text { weeks of birth }\end{array}$ \\
\hline Florence & Halliday & Sec. Complete & 1 & $\prime \prime$ & NP & - & IC & , \\
\hline Jiapu & Ibanigo & No Education & " & TBA/HC & - & $\mathrm{IC}$ & NIL & $\begin{array}{l}\text { Spontaneous } \\
\text { Abortion }\end{array}$ \\
\hline Nwikilaka & Wilson & Pri. Complete & Third & TBA & NP & - & NIL & $\begin{array}{l}\text { Mother and baby } \\
\text { survived after } 6 \\
\text { weeks of birth }\end{array}$ \\
\hline $\begin{array}{l}\text { Awolaniofor } \\
\mathrm{i}\end{array}$ & Allison & Sec. Complete & $\prime \prime$ & $\prime \prime$ & NP & - & IC & Maternal Mortality \\
\hline Elizabeth & $\begin{array}{l}\text { Manilla } \\
\text { Pepple }\end{array}$ & No Education & " & " & - & $\mathrm{IC}$ & NIL & $\begin{array}{l}\text { Mother and baby } \\
\text { survived after } 6 \\
\text { weeks of birth }\end{array}$ \\
\hline Ewarigbo & $\begin{array}{l}\text { Dublin } \\
\text { Green }\end{array}$ & Pri. Incomplete & " & " & NP & - & NIL & ( \\
\hline Manila & Long John & $\begin{array}{c}\text { Sec. } \\
\text { Incomplete } \\
\end{array}$ & " & $"$ & NP & - & NIL & , \\
\hline Ajalolo & Wilcox & Pri. Incomplete & $\prime \prime$ & $\prime \prime$ & - & IC & $\mathrm{NP}$ & II \\
\hline
\end{tabular}

HC - Health Centre

TBA - Traditional Birth Attendant

NP - Normal Pregnancy

IC - Identified Complication

NIL - No Changes in

Pregnancy Status 
Identifying cases in the first trimester was difficult due to very low antenatal attendance. It shows that a large number of pregnant women in Ibani community do not begin prenatal visits early in their pregnancy. For instance, all the women that belong to the first-trimester group were identified in the third month of pregnancy when they began prenatal visits. This lateness in utilizing available prenatal care facilities is attributable, on one hand, to the perception that the first two months of pregnancy are inherently safe and the inability to readily defray the cost of prenatal and delivery services, on the other. One of the respondents in this group observed that "there is no need wasting one's time and money on prenatal care before pregnancy is ten weeks old". The implication is that close monitoring necessary for the period is undermined. This attitude probably explains the high rate of Types 2, 3 and 4 pregnancy outcomes among the people.

The next category of cases comprises eight respondents in the second trimester. Like the earlier category, their educational qualification ranged from primary to secondary. Table 2 shows that six of these women patronized TBAs without recourse to any other source for prenatal care services. However, two of the respondents registered with TBAs in addition to health centres for prenatal services. Observation reveals that the reality of the situation is such that health centres located in Ibani villages are grossly inadequate, in both personnel and facilities, for necessary prenatal activities, This may have accounted for why none of the respondents in all the categories represented in the table registered with health centres alone. However, the preference of TBAs is culturally founded.

Table 2 also indicates that five of the respondents in this category had normal pregnancy record on identification, while three had complications. We present here two interesting cases: Nwaeresi and Erengesi represent an almost contrasting picture. As shown in the table, similarities between the two cases exist only in terms of their identification at the second trimester and partly with regard to using the same source for prenatal care (TBAs). However, the former moved from the NP to IC status, and eventually recorded undesired pregnancy-outcome, specifically stillbirth. The latter transited from IC to NP, and finally had desired pregnancy-outcome. On why she started attending antenatal clinic in the fifth month, Nwaeresi explained: 
I went to register with that TBA (pointing at the woman) this fifth month of my pregnancy because I had not noticed any sign that indicates danger ... during my first pregnancy, I had to register in the second month because there were series of body changes I did not understand and for which I was very scared (two months after her identification for the study, she had still birth) ... surprisingly, after about 7 weeks that I met you (referring to the author) there was sudden change in my health, I started noticing drops of blood in my urine and it kept increasing even after consulting with the midwife ... at a time, I was even praying that that I better die than suffering continuous restlessness that characterized my health ... finally, I gave birth to a premature lifeless baby. That situation has remained incomprehensible to me but I thank God I survived the terrible experience. Even though I also registered with a health centre (HC), I still prefer this mama (referring to the TBA) ... could you imagine that the midwife at the $\mathrm{HC}$ was not able to distinguish my babies placenta from that of another baby that was born almost simultaneously; I am not confident it was the right one that was buried. That carelessness is not expected of an Ibani woman considering the importance attached to its proper burial.

The outcome of the above pregnancy could be attributed to the cumulative effects of Nwaeresi's the non-use of maternal facilities in the early months of pregnancy. The implication of the respondent's experience is that a woman's perception of her health status largely influences her prenatal care seeking behaviour. The danger inherent in this attitude is that minor complications that could be managed before they become lifethreatening are undermined. It may be misleading to conclude that women who begin antenatal clinics from the fifth month or even beyond experience more complications and types 2,3, and 4 outcomes than those who begin such clinics earlier. Although the likelihood is high, nevertheless, it depends largely on individual and communal factors. Among the Ibani particularly, the choice of place of prenatal and delivery care is usually determined by the readiness of facility managers to observe cultural values of kindness and sensitivity to handling the placenta. Attaching strong emphasis on placenta, for instance, means that notwithstanding the competence of a Birthattendant/facility, clientele would be low relative to facilities that place a high premium on placenta.

Erengesi was compelled by complications to start attending prenatal clinic in the $21^{\text {st }}$ week of her $5^{\text {th }}$ pregnancy. Prior to the present pregnancy, she did not register officially with TBAs except at the point where labour was suspected. This practice is in tune with her view that "most women who register very early do so either to avoid work or as means of getting money from their husbands". She recounts further: 
I know that every pregnancy has its own peculiarities and demands. My earlier pregnancies did not pose any risks for me, but this one has dragged me to the midwife ... I experience unusual movement in my womb and I don't sleep well and you know when you don't sleep well at night your mind will tour round the whole world. In addition, I experience intermittent breathlessness and general weakness of the body. The TBA has assured me that these are minor problems that will take her few days to rectify (on a second visit few weeks later she noted)

... I am almost completely okay except that occasionally signs of the problems recur $\ldots$ a week after the $8^{\text {th }}$ month, I began to feel every inch okay until my successful delivery. When an Ibani woman is careful to observe the prescriptions and proscriptions related to pregnancy, she is about 95 percent certain of safe delivery.

The statement reveals that the timing of utilization of prenatal care services among some Ibani women is consequent upon their perceived health status. Such perception, it can be argued, is related to ignorance and the influence of socio-cultural variables on the people. The narrative shows that Erengesi's health status improved gradually overtime, a situation attributed to adherence to expert (TBA) advice and prescriptions. That level of certainty emphasized by the case becomes dangerous when pregnant women ignore other activities that affect pregnancy outcomes such as the competence of birth attendants and early commencement of prenatal activities among others.

For Nwanyinnaya and Jiapu, the statuses did not change and the outcomes were perinatal death and spontaneous abortion respectively. The case of Ekeremo is an expected Type-1 outcome given that her NP status did not change throughout the period of pregnancy. Surprisingly, Florence whose status changed from NP to IC also recorded Type-1outcome. A closer observation of the table reveals that even though transitions in statuses were evident among cases in this category, it however indicates, in the final analysis, a kind of balance in the number of NPs and Type- 1 outcomes - an equilibrium that would not readily be attributed to specific factors. In all, five of the respondents in this category experienced Type- 1 pregnancy outcome while three had Types $2-4$ pregnancy outcomes in various forms. In sum, women in this category unlike the earlier category were easily identified. In addition, for most Ibani women prenatal care should actually start anytime within this trimester. 
A total of six women were included in the third trimester category of pregnancy. Like the first category, all the respondents attended prenatal care with TBAs. Table 2 shows that at the time of identification, four of the cases were experiencing normal pregnancy while two were established cases of complications. It is equally indicated that Awolaniofori's pregnancy status changed from NP to IC and eventually ended in maternal mortality. Conversely, Ajalolo was experiencing complications on identification but later recovered and subsequently recorded Type-1outcome. Implicit in these cases is the impingement of individual and communal factors on the people's perception, attitude and behaviour.

Table 3 shows the summary of pregnancy outcomes among the 19 identified cases displayed earlier in Table 1 above. 
Table 3: Distribution of Cases by Types of Pregnancy Outcomes

\begin{tabular}{|l|l|l|l|l|l|}
\hline N & $\begin{array}{l}\text { Cases by } \\
\text { Names }\end{array}$ & $\begin{array}{l}\text { Type 1 } \\
\text { Mother and } \\
\text { Baby Survived }\end{array}$ & $\begin{array}{l}\text { Type 2 } \\
\text { Mother } \\
\text { Survived but } \\
\text { Baby Died }\end{array}$ & $\begin{array}{l}\text { Type 3 } \\
\text { Spontaneou } \\
\text { s Abortion }\end{array}$ & $\begin{array}{l}\text { Type 4 } \\
\text { Mother Died } \\
\text { but Baby } \\
\text { Survived }\end{array}$ \\
\hline 1. & Ibifa & & & $\mathrm{X}$ & \\
\hline 2. & Ikpo & $\mathrm{X}$ & & & \\
\hline 3. & Dimanye & $\mathrm{X}$ & & & \\
\hline 4. & Gberebima & $\mathrm{X}$ & & & \\
\hline 5. & Edith & $\mathrm{X}$ & & & \\
\hline 6. & Alale & $\mathrm{X}$ & & & \\
\hline 7. & Nengi & $\mathrm{X}$ & $\mathrm{X}$ & & \\
\hline 8. & Nwaeresi & & & & \\
\hline 9. & Erengesi & $\mathrm{X}$ & $\mathrm{X}$ & & \\
\hline 10. & Nwanyinnaya & & & & \\
\hline 11. & Ekeremo & $\mathrm{X}$ & & & \\
\hline 12. & Florence & $\mathrm{X}$ & & $\mathrm{X}$ & \\
\hline 13. & Jiapu & & & & \\
\hline 14. & Nwikilaka & $\mathrm{X}$ & & & \\
\hline 15. & Awolaniofori & & & & \\
\hline 16. & Elizabeth & $\mathrm{X}$ & $\mathrm{X}$ & & \\
\hline 17. & Ewarigbo & $\mathrm{X}$ & $\mathrm{X}$ & & \\
\hline 18. & Mannila & $\mathrm{X}$ & & & \\
\hline 19. & Ajalolo & & & & \\
\hline
\end{tabular}

Table 3 shows that out of the 19 women examined as case-studies, only 1 case of maternal death was recorded. Two of the cases fell within the Type- 2 outcome, while those that experienced Type- 3 outcome were equally two. Findings from cases-studies confirm that maternal and infant mortality and morbidity are high among the Ibani of Rivers State. It was particularly indicated that TBAs are about the only prenatal care providers among the people. Pregnancy outcomes among the Ibani can further be illustrated in the resulting pregnancy-postpartum corridor. 


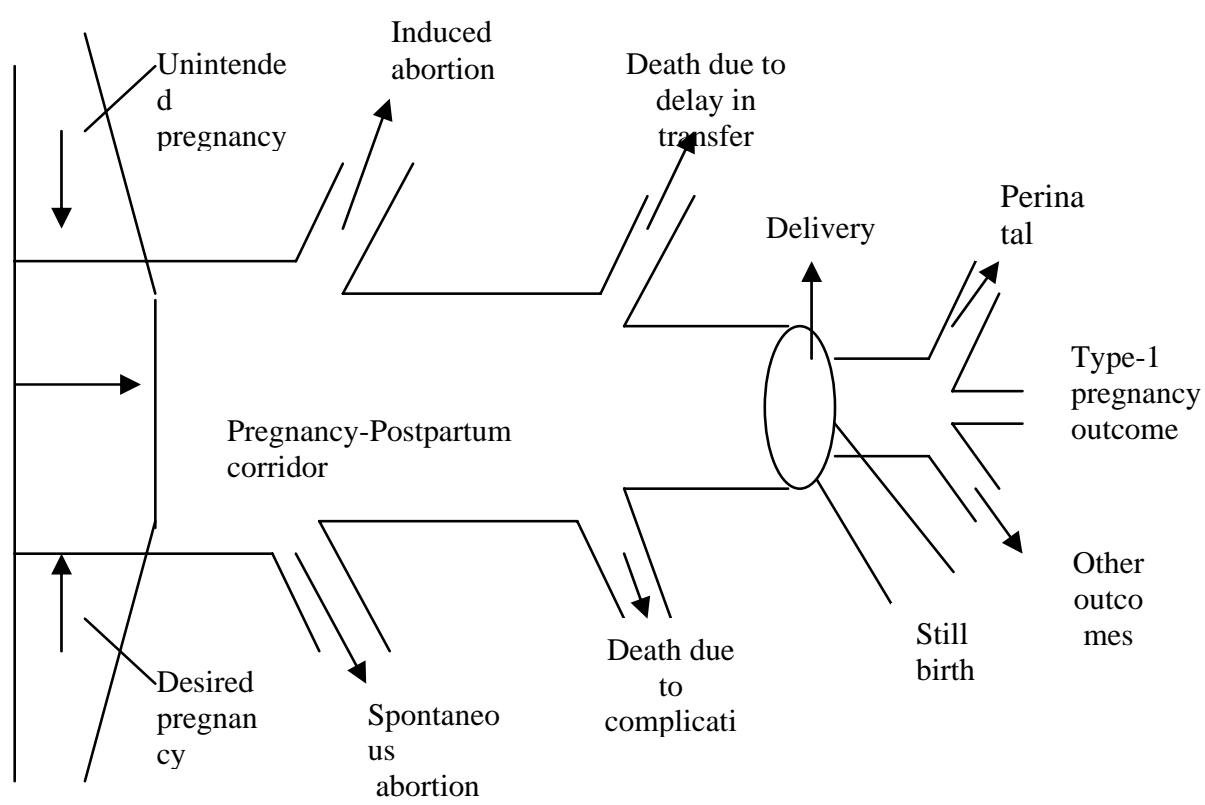

\section{Figure 1: Pregnancy-Postpartum Corridor}

Figure 1 shows that pregnant women enter the pregnancy-postpartum corridor and experience various outcomes. For instance, some women had spontaneous and induced abortion, some died due to complications, others experienced stillbirth, perinatal death, among others. As shown in Table 3, the two cases of spontaneous abortion and stillbirth out of 19 constitute 10.5 percent apiece. Table 3 shows one case of maternal death or Type-4 (5.3 percent of all cases). Those who had Type-1 pregnancy outcome (or the survival of both mother and child) are 14 or 73.6 percent of the total number of cases.

The diminishing nature of the corridor could be attributed to various outlets as a result of types 2, 3 and 4 outcomes. The narrowness is determined indirectly by some factors in a particular environment. For instance, it has been shown that about 35 percent of women in developing countries do not receive prenatal care during pregnancy and almost 50 percent give birth without the assistance of a skilled attendant (WHO 1998). With Nigeria accounting for 10 percent of world maternal mortality (Okolocha, et al., 1998), it is clear that the point at which Type-1 pregnancy outcome is experienced in the corridor is significantly narrow. 
For most developed nations, the corridor does not narrow down noticeably. In places with very high Type- 1 pregnancy outcomes, the difference between the number of pregnancies and Type- 1 outcomes is negligible. The implication is that in such countries, maternal health facilities including personnel are adequately available and also utilized by pregnant women. In specific terms, in Spain and Hong Kong, only 1 out of every 9200 women that give birth dies; for Switzerland, it is 1 in every 8700 women; Canada's record is 1 in 7700; Norway is represented as 1 out of every 7300 women among others (UNICEF 2000; WHO and The World Bank 1997). By contrast, sub-Saharan African data indicate very high levels of maternal mortality. The figure for Nigeria is 1 out of every 13 women (WHO and The World Bank 1997). We now examine some of the cases in detail in order to highlight the influence of socio-cultural factors on pregnancy outcomes among the Ibani:

\section{Case One}

Her name is Ibifa from Ibanigo village. She was 36 years old when the study was conducted. Her highest level of education is primary school and she is engaged in fishing as her profession from which she makes an average of $\$ 6,800$ per month. She got married at the age of 25 and started procreating almost immediately. Although a Christian, she holds traditional beliefs related to Nwaotam festival, disposal of placenta after child birth, etee-te (local gin) consumption, avoidance of beverage and bottled water and pregnant women not coming out at night without a knife on hand to fight dangerous spirits sacrosanct.

These beliefs shaped her perception, attitude and behaviour. For instance, as one's level of education and age at marriage could have combined influence on a woman's fertility rate and her predisposition towards family planning, contraceptive use and child spacing, so also could a woman's beliefs and practices also impinge on her activities during prenatal, delivery and postpartum periods. The experience of most Ibani women confirms this inseparability of pregnancy and pregnancy outcomes from the socio-cultural environment in which they occur. According to Ibifa,

I was born in 1968 in Finecountry Bonny and I attended primary school at this same village. I could not proceed to secondary school not because I was not intelligent but partly because we did not have any such school at the period and also due to the fact that my brothers had to move to my maternal home (Adongo Hart) to be able to attend a mixed school ... moreover, my parents were not ready to let me leave my village because 
I helped them in drying fishes for sale; it was our only source of livelihood... I got married in 1993 to a man who also is a fisherman; I inevitably had to continue with fish smoking ... the present pregnancy is the sixth; I thank God that all my children are alive. This Mama (referring to the TBA that took care of her during all her pregnancies) is so good. In fact, she is God-sent and no matter what your problem is regarding pregnancy, she will tell you what to do ... the number of people you see here attests both to her kindness and competence. I came to see her because I am feeling some terrible pain around my womb and I notice drops of blood when I urinate; I do not have doubts that she will have answer to the problem which she is referring to as minor. Ordinarily, I wouldn't have come this early for medical examination; usually I come in the fifth month of pregnancy.

However, after six weeks of her identification as a respondent for the study and precisely at the $18^{\text {th }}$ week of her pregnancy, she suffered spontaneous abortion. The TBA alleged carelessness and delay on the part of the respondent as being responsible for the outcome. It can be deduced from the respondent's statement that absolute confidence in the ability of the TBA to take care of all maternal related complications at any stage of pregnancy is a deterrent to early antenatal care. A connection could also be established between the respondent's level of education and her attitude to prenatal care. Women who are well educated (high school education) are more likely to experience more Type-1 pregnancy outcome than those who are not. The United Nations (2000) also noted this when it contended that women's subordinate socioeconomic status in terms of education, involvement in reproductive health decisions and work contributes to pregnancy outcomes other than the Type-1. Implicit in Ibifa's statement is that Ibani men prefer to send their sons to school rather than daughters in situations that require choosing between the sexes, a somewhat allusion to male-child preference. However, a male respondent from the same Ibanigo village argued that "men can only do that in a bid to protect their vulnerable daughters from some stress/danger which males could effectively grapple with such as engaging in fishing, or related activity, after a long trek from school".

\section{Case Two}

Gberebima was born in 1965 in Allison village to parents who belonged to the fishing profession. She completed her primary school education, which was her highest level, at age 14 and became fully engaged in fish-smoking. Being the oldest born in a family of eight she got married when she was 23years old to a man from Dick Tolofari. Her husband is employed as a messenger with an oil company in Bonny town; she obeys his instructions to the letter just as the mother obeyed 
her father. As a fisherwoman she earns an average of $\$ 9,000.00$ per month. She is officially a Christian even though most Sundays she is engaged in fishing. Her beliefs and practices include: that placentas should be "properly" buried beside an economic tree; pregnant women should neither, for any reason, sight Nwaotam masquerade nor drink bottled water and so on.

Gberebima's situation shows that she completed primary school at an age that is above normal for that level of education. Her inability to enrol in secondary education for close to a decade after primary school, coupled with the quest among most first daughters to marry early, accounted for her marriage at age 23. She argued: "when first daughters marry early, it opens the nuptial gate for their younger siblings; behaving well assures bachelors that other members of their families will toe similar line". She explains:

It was during my second pregnancy that I experienced this type of swelling. I am surprised that that could re-occur after I have had several other pregnancies without problems. In fact, I did not want to visit the TBA because the problem is minor ... my husband insisted I should see the attendant. Ordinarily, I would have used the money for other things. I had to start coming here because you dare not disobey your husband so that he does not abandon you when he is most needed. I am sure the midwife (referring to the TBA) will handle my case effectively. I visit her every four days for examination and possible advise on what to do (at a later period, during one of the follow-up visits, she had become normal and fit to undergo the rigours of labour and delivery) ... am now very okay and the midwife has confirmed it and in matter of weeks, by the grace of God, I will have my baby. The baby is female ... am sure, several signs attest to that. You may not understand it but I have gone through this process so many times (her prediction regarding the baby's sex was eventually right)

The TBA attributed the success of the outcome to the respondent's strict adherence to expert advice. But the woman's attitude to prenatal care was implicitly influenced by her husband's insistence on early treatment. On further enquiry, the respondent revealed that she discontinued with drinking bottled water and beverage of any kind which the Ibani perceive to affect babies before they are born. She admitted that her husband persuaded her to quit taking these proscribed drinks.

It is also important to note the certainty with which the respondent predicted the sex of the baby by relying on "native intelligence" and past experiences. An orthodox medical practitioner who, instead, ascribed that to co-incidence questioned the consistency of such prediction. He argued: 
Most of these women are funny and usually make predictions for each pregnancy, which have in most cases failed ... some will even to tell you what the sex of a baby will be from the very first month of pregnancy. This is usually the case for women who desire a particular sex of baby and who believe that claiming that sex would cause the gods to give them their desired baby sex wise. Their claims are, however, laughable because even in conventional medicine such level of accuracy has not been attained.(Dr. Ajokuli, 18/06/04: Pers.Comm.)

The above statement is a confirmation of strong attachment of the Ibani to customary beliefs and practices, on the one hand, and the perceived divergence of orthodox and traditional medicine, on the other. Although case two predicted the sex of her baby correctly, in health matters, the correctness of such predictions is usually co-incidental and could mislead an individual to a dangerous dimension.

\section{Case Three}

Nwanyinnaya was born in 1976 in Ndoki, Abia State, to parents who were both involved in business in city of Aba until late 1980's. When she was 7, she was given to foster parents residing in Bonny-town. She had her elementary education at Wilcox village and afterwards began fish-smoking till she got married to a man from Dublin Green in 2002. Ndoki people share similar culture with the Ibani, having migrated from Ibaniland. For instance, Nwaotam ceremony is also celebrated by the Ndoki; their marriage rites are similar and most of their beliefs and practices are the same. Nwanyinnaya did not find it difficult to adjust fully to Ibani culture.

According to Nwanyinnaya, who was carrying her first pregnancy:

I started noticing about two weeks ago ( $15^{\text {th }}$ month into her pregnancy) that my legs were swelling and body temperature was stably high. In addition, I lost appetite ... initially I thought it was malaria or typhoid fever but the midwife taking care of me felt otherwise, even though she did not mention any particular thing (complication/sickness). Her instruction was that I should be strolling around the village, especially at night, in addition to some prescribed herbs (in a follow-up visit 6 weeks after she admitted) ... the situation did not improve much except that the midwife gave me some purgative, which later contributed in improving my appetite. (A month after her delivery, she stated barely holding tears) I had very prolonged labour 
before I eventually delivered the baby girl that showed obvious signs of weakness and hardly cried for the first two days it lived ... it was unfortunate that my labour started during the Nwaotam festival, which constrained me automatically to my house. It is unthinkable for pregnant women to see that masquerade whether intentionally or accidentally; nobody dreams undergoing cleansing usually presided over by the Ikuba priest.

In addition to confirming the above maternal outcome, the TBA associated the incident to lateness in attending prenatal care clinic. The failure to either utilize maternal health facilities or late utilization is linked to a range of factors among individuals and contexts.

Evident in Nwanyinnaya's case is that her inability to access maternal health facility at such a critical period accounted for the type- 2 outcome she recorded. Even though the belief related to Nwaotam ceremony is held sacrosanct among the Ibani, some women would still prefer undergoing the egg-cleansing ritual to experiencing prolonged complications. That would mean weighing the costs and benefits of a particular action where alternative exists. Impliedly, individual perception and values dictate his/her rationality in any given context. To some extent, one's experience also shapes his/her perceptions and attitudes. Nwanyinnaya may have stuck to prescribed norms related to the custom because she was just experiencing her first pregnancy without prior complications. That incident has reshaped her views. She stated: "God forbid, but should a similar situation arise in future, I wouldn't hesitate rushing to my attendant and damn the consequence".

\section{Case Four}

Florence was born in Manilla Pepple village but was married to a company worker from Halliday when she was 28 years old. Her mother, after having 3children, remarried to her father to give birth to 6 others; she is the fourth. The parents preferred financing the education of females while the boys were fully engaged in fishing. She is a trader by occupation with an average monthly income of N16,000. Notwithstanding her relatively high income, the husband's authority is still supreme in household matters even though occasions might call for disobedience. Although she is a Christian, her attachment to traditional beliefs and practices is unshaken. She does not understand why some women would stick to marriages that had lost all the substance of happiness. 
Florence's case is interesting for some reasons. First, that preference for male education among Ibani parents is a matter of choice given personal perception and values. The importance of female education in reproductive health is well highlighted in literature. Education is strongly related to family planning, contraceptive use and recognition of symptoms of complications. Second is that although male-dominance is explicit in Ibaniland, individual orientation and preferences still impinge on its sacrosanctity. The need for women to ignore men's views in some reproductive situations is that they understand better their health conditions more than men. While men's opinion matters, women who are directly affected by reproductive health need to contribute significantly to related decisions. Her experience in the following statement shows that joint decisions are usually better than those made by individuals as individuals. She narrates:

It was God that saved me from death ... I have always prayed against such death (maternal) because it is the worst way to die. It was really surprising that after several months of stable good health I started having problems especially with the positioning of the baby ... it was as if the baby was stuck somewhere it could not move freely ... the TBA as a result was massaging my abdomen almost on daily basis in order to normalize the condition. She was equally assuring me that I was going to give birth safely ... like miracle the labour was the least prolonged of all my pregnancies (the present being the sixth) and I had my very healthy baby (Tamuno). My TBA is God-sent and knows what to do at the right time ... she is patronized by virtually every pregnant woman within and outside this village. Her charges are moderate; she is accessible because she is not engaged in other economic activities and she is most caring. Moreover, she is very experienced (she is about 76 years old and started attending to pregnant women before age 40). Initially, I did not want to patronize her because I felt the other attendant in Ibanigo village was better. My husband insisted. He even warned that I stand the risk of being abandoned if I did not visit the TBA; when I started, I found out that my husband was actually right.

The above case re-echoes the need to utilize the best facilities and personnel available within a given setting which would most likely lead to effective management of complications and the averting of avoidable negative maternal outcomes. 


\section{Case Five}

Awolaniofori was born in 1963 at Wilcox village to parents who were both of the fishing profession. Born into a family of seven, she completed secondary school education and was immediately after engaged in fish-smoking and selling to augment the family resources. She latter got married to a carpenter from Allison village at age 26. Her husband later married a second wife. She continued with her activity/trade even during pregnancy recording an average monthly income of N8, 000. Although her husband had another wife, she nonetheless contributed to the financial up keep of the larger family. She valued Ibani traditional beliefs and practices, such as emphasizing the need for pregnant women to hold knife while coming out at night to be able to fight spirits, avoid sighting the Ibani masquerade, not to drink any form of bottled water and male supreme-authority in household decisions.

The attitudes and behaviour of this case, implicitly or explicitly, were guided by these values. The perceived inviolability of norms guiding the popular Nwaotam festival has implications for maternal health seeking. The consequences of late access and use of health facilities on pregnancy outcomes are enormous and well established in literature (see Adeyeye, 2001). For the present case, although her husband played a notable role in ensuring early treatment, she had type- 4 pregnancy outcome. Precisely two months after identification, her status changed from NP to IC. She noted in a follow-up interview:

When we met last time I told you how healthy I was, but my situation suddenly changed after some time ... my baby, I have been told is not well positioned; at a time I had severe bleeding and the pregnancy was almost lost, it was by the grace of God that I was saved. I now frequently visit my TBA... my husband continually reinforced the need for regular antenatal care in addition to observing the dos and don'ts of pregnancy. In fact, even though I started antenatal clinic in the $5^{\text {th }}$ month, I can tell you that I have visited the clinic more than most people that started in the second or third month (in a follow-up three months later, the author was told the woman died of convulsion-related complications few hours after delivery).

Further enquiry revealed that the deceased was carrying her $9^{\text {th }}$ pregnancy for her third husband. For this woman, a combination of high fertility, pregnancy-related complications and lack of adequate maternal health facilities led to Type-4 outcome. 


\section{Discussion}

High fertility among the Ibani like most other communities in Sub-Saharan Africa is explained by the value for children and large family size. In the case of the Ibani, where re-marrying among women is allowed, each union makes a new demand on the woman in terms of fertility. This implies that multiple marriages have significant relationship with pregnancy and high fertility. Nwokocha (2003b) observed that in most patrilineal societies, male child preference is a recurring syndrome which establishes the legitimacy of marriages. It is apparent that where such legitimacy is tied to fertility, women strive to give birth even in conditions that threaten their lives (Arkutu, 1995).

A combination of factors has been identified as affecting pregnancy outcomes among the Ibani. This is clearly demonstrated by the experience of one of the respondents identified in the second trimester. She recalled:

I started coming here (TBAs place) for checkup last week (in her 19th week of pregnancy) because I have to. Ordinarily, I am very okay but one has to be massaged at various intervals to ensure that both mother and baby are healthy. I know some women who when they feel they are healthy do not go for prenatal visits at all ... what is most important is for a pregnant woman to feed well and be able to recognize changes in her health condition and also seek care when necessary ... for one to really do that, the man (one's husband) would have to encourage his wife by paying for her prenatal care and also helping in household activities ... pregnant women are not supposed to undertake strenuous activities in order not to experience spontaneous abortion or miscarriage. Most Ibani men would not provide their pregnant wives with any form of financial support during pregnancy. These women would not have any alternative to continuing their normal economic activities even late into pregnancy. The surprising thing is that Ibani people consider this attitude normal. For some considerate men, their pregnant wives are not allowed to engage in fishing at the period but rather smoke the fishes caught by their husbands during fishing expeditions. (Nengi: aged 32 and carrying her $6^{\text {th }}$ pregnancy)

The above statement shows that nutrition; male role and the activities of women during pregnancy are defined by individual values and the environment in which they occur. For instance, patriarchy influences the level and type of orientation and occupation available for women. In the above instance, men's insensitivity during maternal periods is circumvented and/ or condoned through society's acceptance of male supremacy over 
women. Such attitude could affect the prenatal activities of women that are not personally able to defray the cost of such services. Moreover, fish smoking which is regarded by the Ibani as less strenuous might actually be more dangerous for pregnant women than fishing itself because it exposes these women to high temperature and vulnerability to complications.

Equally, the extent of female involvement in religious and political activities and household decisions, including reproductive health, is subsumed within patriarchal definition (Nwokocha, 2003a). The implication is that the activities of spouses in most Nigerian communities are divided strictly along sex lines. The danger with such rigidity is that even when it is imperative to adjust some behaviour, a spouse may still not want to go beyond his/her normatively ascribed role. An average Ibani woman, for instance, feels very reluctant to pay for the cost of her prenatal care services perceived as an exclusive male responsibility, even when it is glaring that the man is financially incapacitated. This attitude, which has admittedly affected spousal communication in some instances, was supported by an IDI respondent who argued that "no matter how poor a man is, he should be able to handle some family financial responsibilities". Some delays or inability to begin antenatal clinics early has been found to stem from such behaviour.

Although male domination in family discourse and decisions is conceived as inherently dangerous in several communities and for so many reasons, Gberebima's case reveals that male authority could in some situations affect the outcomes of women's activities positively. Perhaps, the woman's indifference to the swelling experienced early in the pregnancy would have resulted in further complications without immediate expert intervention resulting from her husband's persuasion.

Awolaniofori's case corroborates the argument adduced earlier for Nwaeresi's Type-2 pregnancy outcome, as resulting from indifference to prenatal care during pregnancy. Beyond the fact that Awolaniofori had several pregnancy experiences and also suffered some complications, it is arguable that early maternal/prenatal care could have led to prompt detection, treatment and or referral of the case before her condition became severe. Severity in the present case, ironically, gave rise to more frequent use of health facilities, additional financial expenses and eventually Type- 4 outcome. The view that several pregnancies make women more knowledgeable about complications is nullified by the risk associated with these pregnancies especially in places with inadequate health facilities. 
The case of Jiapu who had "no education" but was conscious of the essence of prenatal care in pregnancy-outcomes - having registered with a TBA and at the village health centre - is an indication that female education does not, in all cases, have consistent association with access to prenatal care services because virtually all the respondents that have higher educational status than Jiapu relied solely on TBAs. Although the respondent experienced prolonged complication that resulted to spontaneous abortion, it was not totally surprising given that Jiapu's status (IC) did not change throughout the pregnancy period. In fact, that outcome could be linked to habit related to food, alcohol consumption, among others seen by the respondent as normal: "I have not done or eaten anything different from our normal food and a little etee-te". This suggests that there is a relationship between nutrition, alcohol and drugs use during pregnancy and cultural environment. When pregnant women are poorly fed, they are exposed to the vulnerability of disease and/or death, which in turn affect their babies. Alcohol consumption during pregnancy is related to hypertension and miscarriage in mothers and low birth weight in infants (Hesperian Foundation, 2001; Acsadi and Acsadi, 1991). For Florence, switching from NP to IC status though characterized by life threatening experiences still did not result in any of Type-2, 3 or 4 outcomes. This case is evidently unique by the fact that among respondents whose pregnancy status was IC prior to delivery, she was the only person that recorded Type- 1 outcome. These findings show that multiple social, ideological and cultural factors affect pregnancy-outcomes among the Ibani and as such impinge on fertility and mortality levels in the area.

\section{Conclusion}

This study has provided data to affirm the links between socio-cultural variables and pregnancy outcomes among the Ibani of Rivers State, Nigeria, by identifying communal and individual values, attitude and behaviours related to pregnancy. Through examination of 19 cases, evidence of the influence of beliefs and practices on pregnancy outcomes, where the activities of individuals are strictly regulated by cultural norms and values, has been demonstrated. The complexities surrounding analysis of these issues signal a need for a holistic understanding of events related to pregnancy. The study argues that although individuals are ascribed some freedom within the social system, in the choice of activities perceived as most rational to seeking Type-1 pregnancy outcome, such independence is unwittingly guided by the norms and values of a society. 
Although the study identified four major types of pregnancy outcomes among the Ibani, further investigation within and outside Ibani society may reveal other types because pregnancy outcomes are relative to times and places. The result of this research shows that the rate of Types $2-4$ outcomes is high among the Ibani. The paper suggests the need for intervention that will re-orientate members of Ibani community to show deserved sensitivity and/ or seriousness to pregnancy and consequent behaviour in order to improve related outcomes.

\section{References}

Acsadi, T. F. and Jonhson-Acsadi, G. 1991. Social and Cultural Factors Influencing Maternal and Child Mortality in Sub-Saharan Africa. New York: Defence for Children International U.S.A., pp. 73 - 96.

Addai. I. 1998. "Demographic and Socio-cultural factors influencing use of Maternal Health Services in Ghana". In F.E. Okonofua and R.C. Snow. eds. African Journal of Reproductive Health. Vol. 2(1): $74-80$.

Adeyemo, A. M. 2000. "Rivers State”. In A.B. Mamman, J.O. Oyebanji and S.W. Petters eds. Nigeria: A People United, A Future Assured, Vol.2.

Adeyeye, O. A. 2001. Socio-economic factors Influencing Access to Reproductive Health Services in Ile-Ife, Nigeria. Being a paper presented at the 10th annual conference of the Population Association of Nigeria (PAN), held between 14 and 17 Oct. Lagos.

Alagoa, E. J. and Fombo, A. 2001. A Chronicle of Grand Bonny. Ibadan: Ibadan University Press.

Arkutu, A. A. 1995. Healthy Woman, Healthy Mothers: An Information Guide. New York: Family Care International.

Banigo, A. O. 1996. Issues Affecting the People of Niger Delta. Port-Harcourt: Ekeremo.

Hesperian Foundation. 2001. Women's Health Exchange: A Resource for Education and Training. California, Issue, Vol. 7.

Isiugo-Abanihe, U. C. 2003. Male Role and Responsibility in Fertility and Reproductive Health in Nigeria. Lagos: Ababa Press.

Okolocha, C.; Chiwuzie, J; Braimoh, S; Unuigbe, J. and Olumeko, P. 1998. "Socio-cultural factors in Maternal Morbidity and Mortality: A Study of A Semi-Urban Community in Southern Nigeria”. Journal of Epidemiology and Community Health, 52(5): 293 - 297.

Moore, K. and Helzner, J.F. 1996. What's Sex Got to go With it?: Challenges for Incorporating Sexuality into Family Planning Programs. New York: Population Council.

Nwokocha, E. E 2003a. Gender and Poverty: Facing the Challenges of the Time. A Paper Presented at the sub-Regional Conference on Gender and Poverty at the Obafemi Awolowo University. Ile Ife Nigeria: Centre for Gender and Social Policy Studies. $28^{\text {th }}-$ $29^{\text {th }}$ May 2003.

Nwokocha, E. E. 2003b. "Male Child Syndrome and the Agony of Motherhood among the Igbo of Nigeria”. Submitted for the South African Sociological Association Conference. Durban: South Africa; June $29^{\text {th }}-$ July $1^{\text {st }}$.

Nwokocha, E.E. 2004. Socio-cultural factors affecting Pregnancy-Outcomes among the Ibani of Rivers State, Nigeria. Unpublished Ph.D thesis. Ibadan: University of Ibadan, Nigeria.

Population Reference Bureau. 2002. Making Motherhood Safer: Overcoming Obstacles on the Pathway to Care. Washington: Population Reference Bureau. 
Salter, C., Johnston, H.B., and Hengen, N. Care for post abortion Complications: Saving Women’s lives. Population Reports. Series L, No. 10. 1997. Baltimore: Johns Hopkins School of Public Health. Vol. xxv (1).

Sen, G.; Germain, A. and Chen, L.C. eds. 1994. Population Policies Reconsidered: Health Empowerment and Rights. Boston Massachusetts: Harvard University Press.

UNICEF. 2000. Safe Motherhood: Current Constraints and Challenges. Sponsored Survey presented at the Health Sector Development Plan Review in Nigeria.

United Nations. 2000. Health and Mortality: Selected Aspects. World Population Monitoring, 1998. New York: United Nations.

Wall, L.L. 1998. Dead Mothers and Injured Wives: The Social Context of Maternal Morbidity and Mortality among the Hausa of Northern Nigeria. Studies in Family Planning, 29 (4)

WHO. 1998. Postpartum Care of the Mother and Newborn: A Practical Guide, Geneva: WHO.

WHO. 2000. Safe Motherhood: A Newsletter of World Wide Activity. Issue 28(1).

WHO and World Bank. 1997. Maternal Health around the World: Facts and Figures. Geneva: WHO. 